\title{
To bleed or not to bleed? That is the question
}

\author{
Yizhan Guo, MD, and Alexander Sasha Krupnick, MD
}

From the Division of Thoracic Surgery, Department of Surgery, University of Virginia, Charlottesville, Va. Disclosures: Authors have nothing to disclose with regard to commercial support.

Received for publication Sept 4, 2017; accepted for publication Sept 9, 2017; available ahead of print Oct 6, 2017. Address for reprints: Alexander Sasha Krupnick, MD, Department of Surgery and The Carter Immunology Center, University of Virginia, PO Box 800679, Charlottesville, VA 22908 (E-mail: sashak@ virginia.edu). J Thorac Cardiovasc Surg 2018;155:436-7 0022-5223/\$0.00

Published by Elsevier Inc. on behalf of The American Association for Thoracic Surgery https://doi.org/10.1016/j.jtcvs.2017.09.039

In this issue of the Journal, Spratt and colleagues ${ }^{1}$ from the University of Minnesota present a simple and elegant method for the collection of autologous blood for ex vivo lung perfusion using the Organ Care System from TransMedics Inc (Andover, Mass). The description provides an easy, step-by-step approach that can be reproduced by any group. At another level, this report brings to light the central question of what is the optimal solution for ex vivo organ perfusion.

As the demand for lung transplantation increases while the number of viable organs remains steady, a greater and greater need develops for novel strategies of expanding the donor organ pool. Over the last decade, ex vivo perfusion of donor lungs has proven itself a valuable and viable strategy for both evaluation of marginal organs as well as organ rehabilitation for augmentation of function. ${ }^{2}$ Exciting developments in this field have raised numerous questions, including the matter and composition of the optimal solution to be used in the perfusate. Perfusion with the hyperoncotic Steen solution, composed of albumin and dextran, is now an Food and Drug Administration-approved protocol of lung reconditioning as adopted by XVIVO Perfusion Systems (Göteborg, Sweden). The first successful series of reports in lung reconditioning and ex vivo assessment by the Stig Steen group used a mixture of Steen solution with blood products to achieve a hematocrit of $\approx 15 \%$. $^{3,4}$ The Toronto group has reported their experience with reconditioning more than 60 lungs using acellular Steen solution without the addition of red blood cells with graft function similar to lungs that did not require reconditioning. ${ }^{5}$ Such data using acellular solution have been reproduced by other groups as well. ${ }^{6}$

Differences in clinical experience have stimulated an interest in translational studies directly focusing on the utility of red blood cells and blood components in perfusion solutions. The Papworth group compared blood-based versus acelluar solutions during a 4-hour ex vivo perfusion of porcine lungs. They were unable to identify differences in oxygen exchange capacity, pulmonary vascular resistance, proinflammatory cytokine production, or histologic organ

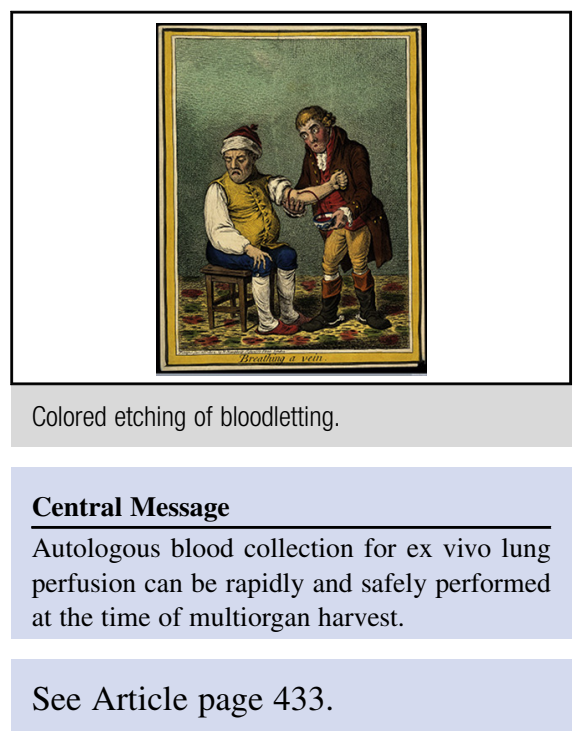

damage between cellular and acellular solutions. ${ }^{7}$ In a different set of studies, however, the Minnesota group demonstrated failure of acellular solutions to maintain lung integrity for periods longer than 8 hours. ${ }^{8}$ Furthermore, the use of whole blood, harvested using similar techniques as described in the accompanying report, allowed for extensive preservation of donor lungs for 24 hours without deterioration of pulmonary artery pressure, oxygenation, or of pulmonary edema. The reason for superiority of whole blood-based perfusate over addition of washed red blood cells is unknown but could be the result of plasma or other cellular components, which may quell circuit-related injury. Although confirmatory data for ex vivo perfusion in other models is limited, military experience in the use of fresh whole blood seems to support its advantage in resuscitation and amelioration of end organ damage. ${ }^{9}$ Thus, until stronger evidence is obtained to the contrary, the decision "to bleed" the donor to obtain blood components to assist in ex vivo perfusion might be the logical choice. The methods outlined by Spratt and colleagues ${ }^{1}$ in this issue of the Journal make adequate blood products just a catheter length away.

\section{References}

1. Spratt JR, Mattison LM, Iaizzo PA, Loor G. The ABCs of autologous blood collection for ex vivo organ preservation. J Thorac Cardiovasc Surg. 2018;155:433-5.

2. Yeung JC, Cypel M, Keshavjee S. Ex-vivo lung perfusion: the model for the organ reconditioning hub. Curr Opin Organ Transplant. 2017;22:287-9.

3. Steen S, Ingemansson R, Eriksson L, Pierre L, Algotsson L, Wierup P, et al. First human transplantation of a nonacceptable donor lung after reconditioning ex vivo. Ann Thorac Surg. 2007;83:2191-4.

4. Steen S, Sjoberg T, Pierre L, Liao Q, Eriksson L, Algotsson L. Transplantation of lungs from a non-heart-beating donor. Lancet. 2001;357:825-9. 
5. Tikkanen JM, Cypel M, Machuca TN, Azad S, Binnie M, Chow CW, et al. Functional outcomes and quality of life after normothermic ex vivo lung perfusion lung transplantation. J Heart Lung Transplant. 2015;34:547-56.

6. Sage E, Mussot S, Trebbia G, Puyo P, Stern M, Dartevelle P, et al. Lung transplantation from initially rejected donors after ex vivo lung reconditioning: the French experience. Eur J Cardiothorac Surg. 2014; 46:794-9.
7. Roman M, Gjorgjimajkoska O, Neil D, Nair S, Colah S, Parmar J, et al. Comparison between cellular and acellular perfusates for ex vivo lung perfusion in a porcine model. J Heart Lung Transplant. 2015;34:978-87.

8. Loor G, Howard BT, Spratt JR, Mattison LM, Panoskaltsis-Mortari A, Brown RZ, et al. Prolonged EVLP using OCS lung: cellular and acellular perfusates. Trans plantation. 2017;101:2303-11.

9. Spinella PC. Warm fresh whole blood transfusion for severe hemorrhage: U.S military and potential civilian applications. Crit Care Med. 2008;36:S340-5. 